\title{
English Phraseological Research on Until By/ Before Working as Complex Prepositions
}

\author{
Ai Inoue ${ }^{1}$ \\ ${ }^{1}$ Associate Professor, Department of Foreign Languages, National Defense Academy, Japan \\ Correspondence: Ai Inoue, Department of Foreign Languages, National Defense Academy, Japan, 1-10-20 \\ Hashirimizu, Yokosuka City, Kanagawa Prefecture, 239-8686. E-mail: aiinoue@nda.ac.jp
}

Received: August 15, 2018 Accepted: September 20, 2018 Online Published: December 27, 2018

doi:10.5539/ijel.v9n1p1 URL: https://doi.org/10.5539/ijel.v9n1p1

\begin{abstract}
This corpora-based study shows that until by and until before, which are newly observed phraseological units (PUs) in contemporary English, function as complex prepositions (CPs). As an interesting phenomenon of present-day English, two prepositions are put together with a single meaning. Specifically, the prepositions in and on co-occur with various other prepositions, and each resulting prepositional phrase becomes established as a new CP with a single meaning like in at or in on. The combinations until by and until before have not been widely acknowledged and have been regarded as mistakes in previous studies. This study shows the meanings of the two phrases, the process of their establishment as new CPs and the way they gained their new meanings. To this end, the study carries out the following research procedures: (i) showing the frequencies of until by and until before in corpora from the synchronic and diachronic perspectives; (ii) differentiating until by and until before by semantically and syntactically clear regarding how until by and until before are used in context; and (iii) showing the kinds of prepositions that are used with until to form PUs as well as CPs.
\end{abstract}

Keywords: corpora-based research, until before, until by, a complex preposition, blending

\section{Introduction}

English has been widely used as lingua franca in a variety of situations. Hence, it is not surprising to find a new English word or phrase, new meanings of existing English words, and new English grammatical changes, which means that English changes at speed. Research on them from various perspectives has been carried out to catch up with the changes and has been revealed in the academic world through publishing papers, books, and dictionaries.

Generally speaking, new English phrases tend to be put together existing English words. For example, in and on that are familiar combine with other familiar words to be in to, on against, in and out, and in and out. The first three combinations behave as complex prepositions, the last one as a complex particle (Please see Inoue 2013a,b, 2014 in detail). Also, in to and on against co-occur with be verb to be be in to and be on against as established phrases. Inoue (2011) discusses until is used with other words into until to and up until to functioning as complex prepositions. The study defines phrases as consisting of at least two familiar English existing words and refer to them as phraseological units (PUs for short).

Other than the above mentioned complex prepositions, one of the recently published English dictionaries, Macmillan English Dictionary, 2nd edition $\left(M E D^{2}\right)$ describe be in at, be in for, be in on etc. under the entry for in and be on about, be on at, be on for, etc. under the entry for on. Oxford Advanced Learner's Dictionary, 9th edition $\left(O A L D^{9}\right)$ includes be in at, be in for, be in with under the entry for in and be on about, be on at, be on for, etc. under the entry for on. Both dictionaries admit only until after as a complex preposition in the case of until. No complex prepositions I have introduced above are included in any dictionaries. In addition, there is not any conclusive research that shows what kinds of words are used with in, on and until as far as I have investigated.

The paper is organized as follows. Section 1 is the overview of the study. Sections 2 deals with the explanations of complex prepositions and of newly observed complex prepositions (i.e., (up) until to) discussed in Inoue (2011). Data used in the study is introduced in Section 3. Section 4 explains research methods the study adopted. Section 5 reveals the quantitative and qualitative actual manners of until before and until by based on the data and the research methods in Section 3 and 4. Also, Section 5 investigates how until before and until by become 
PUs. The implication of the study is shown in Section 6. My conclusions are drawn in the final section.

\section{Previous Research}

Previous research has regarded until after as acceptable as is shown in (1), but until before and until by as unacceptable as far as I have investigated. Please note that explanations in (1) are ones concerning the pattern [a preposition until] + [a conjunction after + clauses], not a complex preposition [until after] discussed in the study. Until after is found 3768 times in Corpus of Contemporary American English (COCA for short), which is one of data used in the study and will be introduced in Section 3. I investigated 1000 examples of until after out of 3768 examples using a function called FIND SAMPLE (randomly choose examples) in COCA, [until after] + a noun (phrase) is observed 554 times. Some easy-to-follow examples are shown in (2) (italicized by the author as in the following.).

(1) a. The preposition until may introduce after-clauses: Don't leave until after I've spoken to you.

(Quirk et al., 1985, p. 1086.)

b. until after is acceptable, but it is better to remove after. Until after is originally constructed as [until] + [after S $+\mathrm{V}]$. For example, I read in my room until after midnight can be paraphrased into until after it was midnight. After can be regarded as a preposition taking clauses as an object (Original in Japanese.).

(Ishibashi (ed.) 1966, p. 1022f.)

(2) a. Even though she knew her mother was a breast-cancer survivor, she put off going to get a mammogram for 13 years. Once diagnosed, she put off treatment until after her summer vacation

(COCA, 2015, News)

b. I had planned not to make a statement until after our divorce trial, which was originally scheduled for November 12th.

(COCA, 2014, Magazine)

Until after in (2) means that an action indicated by a verb in each sentence (i.e., put off in (2a), make a statement in (2b)) is done after an event or time in noun phrases coming after until after. Hence, until after functions as a complex preposition.

According to previous research on before, by, and until, before is used as 'earlier than something or someone, ahead of someone or something else in a list or order' (quoted from Longman Advanced Dictionary of Contemporary English, 6th edition $\left.\left(L D C E^{6}\right)\right)$, by as 'no later than a particular time or date' $\left(M E D^{2}\right)$, and until as 'happening or done up to a particular point in time, and then stopping' $\left(M E D^{2}\right)$.

2.1OED ${ }^{2}$

$O E D^{2}$ includes the 11 examples of until by. Its first example appeared in 1643 , afterward, in 1759 , in 1835 , in 1839, in 1844, in 1845, in 1861, in 1969, and in 1971 (two examples were found). One example is used in an explanatory text, it is impossible to mention when it was used. Please observe (3). Until by in (3a) is first observed, it in (3b) is used in an explanatory text, it in (3c) is used as the last example.

(3) a. 1643 Milton Divorce (1851) Introd. 4 Custom.. rests not in her unaccomplishment, until by secret inclination she accorporat herself with error.

b. In ME. these forms were gradually eliminated or reduced, until by 1200 in some dialects, ....

c. 1971 Ink 12 June 14/1 Bernie's salesmen kept bringing in the loll .. until by 1970 they had \$2.4 billion in their management kitty.

Until by in (3) means to remind 'no later than' by combining with semantically similar words, until and by and works as a complex preposition because it follows a noun (phrase).

(4) is a single example of until before in $O E D^{2}$.

(4) 1951 Chicago Daily News 17 Jan. 34/3 The former player said he would not know until before the game what the final betting 'spread'- the difference in the point score - would be.

Similar with until by, until before is used to say 'no later than' by putting together the meanings of until and before and co-occurs with a noun into a complex preposition. $O E D^{2}$ includes the limited examples of until before and until by, it is difficult to assert the actual manners of until before and until by. 


\subsection{Complex Prepositions (CPs)}

\subsubsection{Basic Notion}

The section stars to explain the types of prepositions.

Prepositions can be classified into the three types: (i) a polysemous single preposition like $a t$, in, of, etc., (ii) a polysemous complex prepositions consisting of two prepositions like into, onto, within, until, etc., and (iii) a monosemous group preposition (Note 1) formed by a preposition and a word like according to, apart from, in accordance with, with regard to, due to, because of, result of, in agreement with, in case of, etc. Group prepositions are further classified into the following three types, (a) [a preposition $1+$ a noun + a preposition 2] (e.g., by means of, in addition to), (b) [a(n) adjective/ adverb/ conjunction + a preposition] (e.g., ahead of, because of), and (c) others (e.g., as far as, as for, thanks to). It is clear from the three types that until before and until by are complex prepositions.

Quirk et al. (1985), Akimoto (1999, 2002, 2005), Quirk \& Mulholland (1968), Hoffman (2001, 2004, 2005), and Tottie and Hoffman (2001) refer to group prepositions as complex prepositions and define group prepositions as consisting of a preposition and a noun into a preposition. Huddleston and Pullum (2002) refer to such group prepositions as 'idiomatic and fossilized expression.'

The study admits word-combinations formed by [a preposition $1+$ (a word) + a preposition 2] as complex prepositions (CPs for short) and defines the CPs as PUs which may be polysemous in accordance with the context in which they are used. CPs used in Quirk et al. (1985), Akimoto (1999, 2002, 2005), Quirk \& Mulholland (1968), Hoffman (2001, 2004, 2005), and Tottie and Hoffman (2001) are referred to as group prepositions in the study.

\subsubsection{Features of Prepositions Used in the Pattern [Preposition - [Prepositional Phrase]]}

Yasui (ed.)(1996) explains the case when double prepositions (referred to as CPs in the study) appear using the example $A$ rabbit emerged from under the table. In this case, the prepositional phrases [under the table] appears as the complement of the preposition from and the example has the inner structure [preposition - [prepositional phrase]] (hence [P-[PP]]). Also, the limited prepositions such as from, until, and since, etc. are used in $\mathrm{P}$ in [P-[PP]]. Please look at the following example concerning until and since.

(5) a. The film lasted until after 11 o'clock.

b. Jack has been in the army since before 1960 .

(Yasui (ed.)1996, p. 346)

Yasui (ed.) (1996) only shows [P-[PP]] in case from is used in $\mathrm{P}$ as is shown in (6).

(6) a. A lark called from across the field.

b. I've removed John's picture from above the shelf.

c. The airport is a bustling, noisy confluence of air route from around the country.

d. Mrs. Samuel Josephs had been watching the scene from behind her drawingroom blind.

e. The sound of gunfire came from beyond the post office.

f. The wide expanse of sand stretched into the Pacific from beneath a brow of rocky cliffs.

g. I took this chair from by the window.

h. The horse galloped from in front of the tree to under the tent.

i. There's a noise coming from inside your car.

j. The vase fell from on the shelf.

$\mathrm{k}$. The documents were shot from out of range.

1. He suspected they might have brought a technical specialist from outside Mexico City.

$\mathrm{m}$. I removed the lamp from over the counter.

$\mathrm{n}$. The sound of gunfire came from past the post office.

o. One of a certain fat boy's friends was ambulanced off late from near the Power Plant.

(Yasui (ed.)1996, p. 347) 
Yasui (ibid.) explains that any prepositional phrases showing positional relation in space can come after from, but that, when the prepositional phrase showing a point in space (i.e. on the shelf) is used after from in (6j), it might be judged that (6j) The vase fell from on the shelf seems unacceptable. The reason why (6j) seems unacceptable is the vase from the shelf is enough to be interpreted as that the vase fell from above because from the shelf is regarded as up in space and fell shows the downstroke movement. On the other hand, it is not acceptable to $A$ rabbit emerged from under the table to delete the second preposition (under) because the PP (under the table) shows spatial existence. If under is removed from the sentence (A rabbit emerged from the table), it is impossible to understand a rabbit comes from under the table. Moreover, Yasui (ed.)(1996, p. 348) explains that English does not have prepositions meaning from inside or from outside, etc. in a single word, so [P-[PP]] such as from the under the table by putting together the preposition showing the point of origin (from) and PP showing a space (under the table) exists.

The explanations in Yasui (ed.)(1996) leads to the fact that until follows after into a CP, until after. However, it is not persuasively argued what kinds of PPs are used with until. The study shows the feature in the later section.

Ando (2005, p. 35f.) admits the existence of [P-[PP]] and shows the examples of [P-[PP]] in (7).

(7) a. The cat came out from behind the screen.

b. He took a box from under the counter.

c. The children played until after dark.

\section{3 (Up) Until to in Inoue (2011)}

Inoue (2011, p. 60ff.) explains that the pattern consisting of [a durative verb/ a stative verb + (up) until to] functions as reminding the addressee that the state or action denoted by a durative or stative verb continues toward the happening, event, or time followed by (up) until to. In case verbs other than a durative or stative verb are used, the pattern of [a verb + (up) until to] works as same as the pattern of [a durative verb/ a stative verb + (up) until to]. Furthermore, no characteristic aspect and tense of verbs in the pattern [a verb + (up) until to] are found in corpora. As the feature of typically co-occurring words with (up) until to, it tends to co-occur with words showing that something finishes such as last or end as is shown in (8).

(8) a. This means that average household size in Great Britain fell from about 3.21 to about 2.56 persons over this period and this decline is expected to continue at least until to the end of the century.

$(\mathrm{BNC})$

b. Simply follow the entry instructions detailed in the how to enter section below. When can I enter the promotion? The 'Coca-Cola' FIFA World Cup? Win Tickets Every Day in June promotion is open from 00:00 on 01.05 .06 and will run until to $23: 59$ on 30.06.06. Prize draws will take place every day between 01.06 .06 and 30.06 .06 (inc).

(BNC)

c. Respected dance music monthly Muzik has printed its last issue. IPC have closed it down after a period of poor sales and advertising revenue. Muzik's year on year circulation decreased $11 \%$ to 36,089 copies in the six months up until to December 2002.

$(\mathrm{BNC})$

Next, let us consider the formation of (up) until to. Please look at (9).

(9) We camped there $\left\{\begin{array}{l}\text { until } \\ \text { till } \\ \text { (up) to } \\ \text { through }<\text { AmE }>\end{array}\right\}$ September.

(modified in Quirk et al., 1985, p. 690)

Till, (up) to, and through can be used as similar as until, all of which show duration. The observation of (9) leads us to believe that (up) to influences the establishment of until to. This is accountable if we consider that blending, especially the blending at a lexical level is working.

According to Yagi (1999, p. 78), the blending at a lexical level is a linguistic phenomenon, which two syntactic different patterns with similar meanings, $\mathrm{A}$ and $\mathrm{B}$ are put together and then a new pattern $\mathrm{C}$ different from both $\mathrm{A}$ and $\mathrm{B}$ is generated. The new pattern $\mathrm{C}$ is used together with the two patterns $\mathrm{A}$ and $\mathrm{B}$. To put it more simply, the 
syntactically and semantically similar prepositions until and to are used together due to the working of the blending at a lexical level, and then until to comes to have been used as a compound prepositional phrase. Up of (up) to is optional, so up until to is not repeatedly used compared to until to. Until to is an unmarked compound prepositional phrase.

To sum up what I have just explained, first, until to is generated due to the blending of to and until. Second, the existing phrase up until is used together with until to in order to make the duration of a verb in a sentence continue toward the happening following until to. Hence, up until to becomes to have been used as a compound prepositional phrase due to the working of the blending. (10) puts the formation of until to, up until to, and from A until to $\mathrm{B}$ into the form of a diagram.

(10) the formation of until to, up until to, and from A until to B

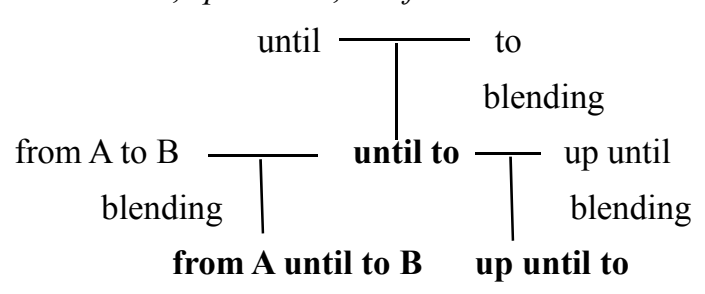

\subsection{Research Questions}

The study tackles the following research questions.

(11) a. To reveal the actual semantic, syntactic, and phonetic manners of until by and until before from quantitative and qualitative aspects

b. Are until by and until before newly observed CPs and PUs?

c. To show the features of prepositions coming after until

\section{Data}

Thanks to the advancement of Internet, a wide range of data in the web are available to us. To investigates the above mentioned research questions, this study uses the data from The Corpus of Contemporary American English (COCA), British National Corpus (BNC), WordBanksOnline (WB) from a synchronic perspective and from The Corpus of Historical American English (COHA) from a diachronic perspective. I accessed COCA on Nov. 30th, Dec., 12th, and 17th in 2017 and BNC, WB, and COHA on Dec., 25th in 2017. In the section 5.2 and 5.5, data obtained from COCA show the register, where each example is used. The acronyms ACAD stands for academic, FIC for fiction, MAG for magazine, SP for spoken, WR for written, and NW for news.

\section{Research Methods Adopted in the Study}

The study is descriptive research which attempts to examine linguistic phenomena concretely and does not depend on any major linguistic theory. The basic thesis on which this research is based is the theory of semantic syntax, i.e., the meaning of a word or a phrase is closely related to the syntactic feature of the word or the phrase.

\subsection{Inner Features to Become a PU - Formation, Process, Criteria, and Stress Pattern Rules}

Inoue (2016) shows the inner features of how a word combination becomes a PU such as formation, process, criteria, and stress pattern rules shown in (12), (13), (14), and (15).

The methods as to how PUs are formed are shown in (12).

(12) PUs

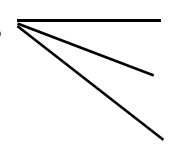

$$
\begin{aligned}
& \text { morphological method (adopting word-formation rules)(Note 2) ... type A } \\
& \text { morphological and semantic method (general linguistic method) ... type B } \\
& \text { semantic method ... type C }
\end{aligned}
$$

(Inoue, 2016, p. 5)

At this point, care must be taken that type B is an intermediary for type A and type C. From this discussion including (12), it can be observed that PUs are formed not as linear constructions but as steric constructions.

From the outcomes shown in (12), (13) summarizes the process as to how a word combination becomes a PU. 
(13) (i) two existing words are put together by adopting either (i) a morphological method, (ii) a morphological and semantic method, or (iii) a semantic method, which then become a repeatedly used unit

\section{$\downarrow$}

(ii) a PU has its own meaning and function through repeated use

$$
\downarrow \leftarrow \text { with the assistance of the lexicalization of phrases }
$$

(iii) the PU is established as an independent lexical item

(Inoue, 2016, p. 6)

As (13) describes, first the PUs are formed through the combination of two existing words, as in the Kenning used in Old English (OE), and shaped using a specific method. Second, the PUs develop individual features through frequent use. With the assistance of phrasal lexicalization, one of the word-formation rules, a PU becomes an independent unit. These processes hold true for all PUs regardless of whether they are continuous or discontinuous.

Criteria for determining whether a word-combination is a PU or not are defined in (14).

(14) a. frequency
b. dispersion
c. fixedness (i.e. no variables)
d. consistency of existing words

Frequency and dispersion (14a, b) are the norms indicating that PUs do not arise by accident. Fixedness (14c) is the necessary condition that indicates that the fixed form of the PU has widespread use in any context or situation, meaning that PUs are polysemic and multifunctional. In (14d), newly observed PUs are formed through a combination of existing words. If such combinations are not frequently and widely used, they are not PUs.

(15) shows the stress patterns of PUs.

(15) a. it is impossible to predict the stress patterns of phrases simply by means of whether a word is a function word or a content word.

b. the stress is placed on the word by which a speaker would like to convey the most important meaning of phrases.

c. set phrases have stable stress patterns as words do.

d. set phrase doesn't necessarily consist of one tone group and each word consisting of set phrases has each tone group.

(Inoue, 2009, p. 133)

Please note that the four rules do not always apply to PUs because until before and until by discussed in the study are comprised two function words.

\subsection{Informants' Elicitation to Investigate the Stress Patterns of Until Before and Until By}

I ask native speakers of English to read the English passages including until before and until by obtained the data collected from the corpora in Section 3 and investigate the stress patterns of until before and until by using the freely available and downloadable software called praat. Then, I show the stress pattern's rules of PUs hold true for until before and until by.

\section{Until Before and Until By}

\subsection{Quantitative Result}

The corpora introduced in Section 3 show the number of until before and until by in Table 1. Please note that Table 1 does not include the examples of [until][before + SV] and those consisting of [until] + [by-phrase] such as [until][by chance], [until] [by and by], [until] [by means of], [until] [by degrees], [until] [by dint of], and [until] [by the chance]. 
Table 1. Frequencies of until before and until by in each corpus

\begin{tabular}{lll}
\hline & until before & until by \\
\hline COCA & 9 & 46 \\
BNC & 0 & 29 \\
WB & 1 & 5 \\
\hline sum & 10 & 80 \\
\hline
\end{tabular}

Table 2. Frequencies of until before and until by in COHA

\begin{tabular}{llllll}
\hline & until before & until by & & until before & until by \\
\hline 1820 & 0 & 2 & 1920 & 1 & 8 \\
1830 & 0 & 6 & 1930 & 1 & 13 \\
1840 & 0 & 11 & 1940 & 0 & 10 \\
1850 & 0 & 7 & 1950 & 3 & 10 \\
1860 & 0 & 5 & 1960 & 0 & 9 \\
1870 & 0 & 10 & 1970 & 0 & 11 \\
1880 & 0 & 8 & 1980 & 1 & 9 \\
1890 & 1 & 6 & 1990 & 0 & 3 \\
1900 & 1 & 11 & 2000 & 1 & 3 \\
1910 & 2 & 15 & & & \\
\hline
\end{tabular}

Table 1 and 2 show that until before started to be used around 1890s, but it has been in low frequency. On the other hand, until by started to be used in 1820s and comes to be widespread used in present-day English.

\subsection{Qualitative Results}

The section argues the semantic and syntactic features of until before and until by.

\subsubsection{Until Before}

(16) is the examples of until before obtained from corpora. A single example of up until before is found in corpora and is shown in (16d).

(16) a. In conversations riddled with coarse language and blunt threats that the FBI recorded with telephone wiretaps and listening devices planted in his campaign office, the governor laid bare a "pay for play" culture that, according to prosecutors, began shortly after he took office in 2002 and continued until before sunrise yesterday, when FBI agents arrested him and John Harris, his chief of staff.

(COCA, 2008, NW)

b. Mrs-GLICK: It - it has. I've actually left my hometown and I've gone away for a couple months, or probably until before the holidays, just to kind of get away from the phone ringing and the doorbell ringing.

(COCA, 2001, SP)

c. There was a little electric charge of excitement in her. You had the sense she was dancing inside. I waited until before dinner to tell Charlie what Hutch had said. We were alone in the cabin, and I knocked on the door of Charlie's room.

(COCA, 1991, FIC)

d. There will be military honors there, just as there were in New York. And the body will be taken here to the library, where it will be open to the public. There will be viewing of the remains for approximately 24 hours after it arrives here this afternoon and up until before the funeral tomorrow afternoon.

(COCA, 1994, SP)

(Up) until before in (16) is used in the syntactic pattern [(up) until before + a noun (phrase) showing time] and is used to mean to ensure that the action or condition implied by the verbs in the sentence which until before appears is done by a noun (phrase) showing time that follows the phrase (up) until before. The noun phrase following (up) until before does not always show the end point of the action, so the action indicated by the verb is not the one down to the wire. Until before combines the meaning of until with that of before and is used to the reminder of the meanings of until and before.

$(U p)$ until before appears in tenses other than future tenses and in any aspects, no frequently used tenses and aspects are found. As the typically co-occurring verbs with (up) until before, continuous verbs like wait and 
continue are used with (up) until before. Similar with (up) until to, until before is formed by the blending of semantically similar words until and before and by the influence of until after, which means that the antonym of after (i.e. before) comes to be used with until. Then, until before and the existing phrase up until come together into up until before. Consequently, (up) until before obtains a function as a CP. The diagram in (17) shows how until before is formed.

(17) until

$$
\begin{gathered}
\hline \begin{array}{l}
\text { blending } \\
\text { the influence of until after }
\end{array} \\
\text { until before }- \text { up until } \\
\text { up until before }
\end{gathered}
$$

I asked native speakers of English (a Canadian, an Australian, an English, two Americans) to read (16) and investigated which word (either until or before) is put on stress using the software praat. The result is shown in Table 3.

Table 3. Stress patterns of until before and up until before

\begin{tabular}{lllll}
\hline & until béfore & úntil before & up until béfore & until \\
\hline$(16 \mathrm{a})$ & 4 & 1 & $\mathrm{n} / \mathrm{a}$ & 0 \\
$(16 \mathrm{~b})$ & 4 & 1 & $\mathrm{n} / \mathrm{a}$ & 0 \\
$(16 \mathrm{c})$ & 4 & 0 & $\mathrm{n} / \mathrm{a}$ & 1 \\
$(16 \mathrm{~d})$ & 0 & 0 & 5 & 0 \\
\hline
\end{tabular}

It is clear from Table 3 that until before and up until before have stable stress patterns; (up) until béfore. Some informants put a pause between until and before and skipped until. The two stress patterns rules of PUs shown in $(15 \mathrm{~b}, \mathrm{c})$ hold true for until before, so it is safe to mention that until before is established as a PU from a phonetic perspective.

\subsubsection{Until By}

Until by collected from corpora is shown in (18).

(18) a. In March 2014, the first known case of Ebola was diagnosed in Liberia. Over the next few months, what started as one case in a border town grew exponentially until by June 30th there were 90 reported cases (Centers for Dis-ease Control, 2015).

(COCA, 2015, ACAD)

b. "The dream kept coming back, you see. First every week or so, and then more and more often, until by the end of September, he wasn't getting any rest when he slept....."

(COCA, 2009, FIC)

c. That was only one of the humiliations he had to endure. They were many, a new one presenting itself almost every hour, and each one stung him like a separate, tiny arrow, until by the end of the day all of him ached with their collected, pricking pain.

(COCA, 2002, FIC)

d. By age twelve, we see that 1 per cent of Timling's women have already married. Percentages married rapidly increase, however, until by age twenty, 60 per cent of women have entered a first marriage.

(COCA, 1993, ACAD)

e. During the 1970s dollar outflows, fluctuating exchange rates and OPEC petro-dollars resulted in an annual growth rate of 25 percent, until by December 1985 the market's gross size was $\$ 2.8$ tril.

(BNC. 1987, WR)

f. The second day here was certainly a lot more "interesting". During our set the sky grew gradually darker 
and darker, until by the last number the sky was as black as the ceiling of the Camden Falcon.

(BNC, 1992, WR)

g. At first she only took an ounce of two of formula at a time. But slowly she took more until by the age of 8 months I was only giving her breastfeeds in the evenings.'

(WB, 1993, WR)

h. Later in the century, especially with the arrival of the power loom in the 1880 's, handloom weaving declined, until by 1900 only 200 blooms still operated, and by 1950 only 4 .

(WB, 1985, WR)

(18) reveals the syntactic and semantic features of until by as follows: until by is used as the syntactic pattern [until by + a noun (phrase) showing an end point]. Semantically, until by is to ensure that the action or condition implied by the verbs in the sentence that until by is used is done by a noun (phrase) implying an end point that follows until by. In other words, until by puts together of the meanings of until and by. Until by tends to co-occur with accomplishment (Note 3) such as grow, decline, and increase, etc., but there are no extinguishing tenses and aspects when the verbs are used. Until by is formed by the two ways: (1)the blending of semantically similar words until and by, and (2)the independently use of until by from the pattern [until] + [by-phrase] such as by the time, by now, by and by, etc. The formation is shown in (19).

(19) until

\section{by}

blending

the independently use from the pattern [until] + [by-phrase]

\section{until by}

Same as until before, I asked native speakers of English (a Canadian, an Australian, an English, two Americans) to read (18) and investigated which word (either until or by) is put on stress using the software praat. The result is shown in Table 4.

Table 4. Stress patterns of until by

\begin{tabular}{lllll}
\hline & until bý & úntil by & until & by \\
\hline$(18 \mathrm{a})$ & 3 & 1 & 1 & 0 \\
$(18 \mathrm{~b})$ & 5 & 0 & 0 & 0 \\
$(18 \mathrm{c})$ & 4 & 0 & 0 & 1 \\
$(18 \mathrm{~d})$ & 3 & 0 & 0 & 2 \\
$(18 \mathrm{e})$ & 4 & 0 & 0 & 1 \\
$(18 \mathrm{f})$ & 5 & 0 & 0 & 0 \\
$(18 \mathrm{~g})$ & 3 & 1 & 0 & 1 \\
$(18 \mathrm{~h})$ & 5 & 0 & 0 & 0 \\
\hline
\end{tabular}

Table 4 shows that until by is the stable stress pattern of the PU until by. Some informants clipped until in the case of until by, which means that by is more semantically and phonetically important than until. Also, same as until before, the two stress patterns rules $(15 \mathrm{~b}, \mathrm{c})$ are applicable to until by, so it is enough to mention that until by is phonetically established as a PU.

\subsection{The Difference Between Until Before and Until By}

The former sections reveal the features of until before and until by summarized into Table 5. Table 5 shows the answer for (11a). 
Table 5. Features of until before and until by

\begin{tabular}{|c|c|c|}
\hline & until before & until by \\
\hline meaning & to ensure no later than & to ensure no later than \\
\hline function & $\mathrm{CP}$ & $\mathrm{CP}$ \\
\hline $\begin{array}{l}\text { a noun (phrase) that follows until } \\
\text { before/until by }\end{array}$ & time (time does not show the end point) & an end point \\
\hline typically co-occurring verbs & durative & accomplishment \\
\hline the way until before/until by is & (1)blending & (1)blending \\
\hline formed & (2) the influence of until after & $\begin{array}{l}\text { (2) the independently use from until }+ \\
\text { by-phrase }\end{array}$ \\
\hline stress pattern & until béfore & until bý \\
\hline
\end{tabular}

\subsection{Are Until Before and Until By Working as Pus?}

It turns out from the examples of until before and until by that they follow a noun (phrase) into CPs. This section investigates whether they are established as PUs.

Until before and until by are formed by using type A in (12) (i.e., blending) and by putting together existing words $((14 d))$. They are fixedly used in registers although they are not frequently used $((14 a, b, c))$. Also, they have their own meanings and functions and have stable stress patterns from Table 3 and 4. Consequently, it is safe to mention that until before and until by are PUs, which is the answer for the research question (11b).

\subsection{Kinds of Prepositions Locating After Until}

This section answers the research question (11c). Table 6 shows the list and frequency of prepositions following until in COCA, BNC, and WB. Please note that prepositions consisting of the pattern [until] + [a prepositional phrase] such as [until] + [for the moment] are not included in Table 6 and that prepositions, after, to, before, and by discussed in previous research, Inoue (2011), and the study are included in Table 6. (20) is the examples of [until + a preposition (used more than five times in corpora)].

Table 6. List and frequency of prepositions following until in COCA, BNC, and WB

\begin{tabular}{llll}
\hline+ prepositions & frequency & + prepositions & frequency \\
\hline after & 2298 & from & 10 \\
about & 415 & half-past & 10 \\
in & 189 & out of & 9 \\
at & 127 & during & 8 \\
near & 88 & before & 6 \\
by & 82 & beyond & 6 \\
around & 77 & inside & 4 \\
like & 37 & over & 4 \\
on & 36 & through & 4 \\
with & 26 & into & 2 \\
toward(s) & 25 & upon & 2 \\
past & 20 & up to & 2 \\
between & 16 & down & 1 \\
to & 15 & till & 1 \\
within & 13 & under & 1 \\
of & 11 & & \\
\hline
\end{tabular}

(20) a. They're getting a new one, but it won't be here until after Christmas. (one and it show popcorn machine.)

(COCA, 2017, FIC)

b. I don't know the word sexual harassment. I don't think I knew it until about 25 years ago.

(COCA, 2017, SP)

c. The Marquesa Fanny lived on productively until in February 1882 aged 77, having dined clad in a fashionable dcolletage, she caught a cold and died. 
d. His company accumulated more and more acres of forestland until at his death in 1914 it owned more than two million acres across Wisconsin, Minnesota, and the Pacific Northwest.

(COCA, 1998, MAG)

e. Tull didn't arrive back with Hortense until near noon of the next day.

(COCA, 2016, FIC)

f. The price rose steadily over the next four months, until by April 1, the eve of the Forestry Conference, it sat at $\$ 500$ - a new record.

(COCA, 1997, MAG)

g. Jester wanted to play basketball in college until around his junior year, when the football recruiting attention became impossible to ignore.

(COCA, 2014, NW)

h. "I just remember going for first chair at 9 a.m., and we'd ride all day and eat supper and then ride all night until like 9 p.m.," says brother Craig McMorris, who will be part of the CBC's Olympic broadcast.

(COCA, 2014, NW)

i. Federal agents launched an 18-month surveillance of Weaver's property, until on August 21, 1992, ....

(COCA, 1995, MAG)

j. Only the by-now-famous Sister Robinson, who made soup every Sunday at the ward for the hungry and homeless, only Sister R. kept calling, e-mailing, praying, until with the help of the bishop and some ex-pats who'd known Kitty for years, she came around.

(COCA, 2017, FIC)

k. She worked until past nine that night, leaving for home when lightning from a sudden thunderstorm flickered the lamp at her desk.

(COCA, 1995, FIC)

1. The figures for productivity are probably somewhat optimistic since alternative estimates indicate no acceleration until towards the end of the period.

(BNC, 1998, WR)

m. To receive full retirement benefits, you must wait until between ages 65 and 67, depending on when you were born.

(COCA, 2008, MAG)

n. All the results provided below are taken from the beginning of the program in July 2011 until to December 2013.

(COCA, 2015, ACAD)

o. But humans did not evolve to be capable of constructing multipart mechanisms until within the last 50,000 years or so.

(COCA, 2009, ACAD)

p. Of course, the vice president and President Clinton did not begin any debates until of October of 1996.

(COCA, 2000, SP)

q. We sat in silence for a moment or two, until from the other table a harsh, cruel laughter broke the early-evening calm.

(COCA, 2017, FIC)

r. "I was very late. My car - it's a van, actually - is old and not very reliable. I had a breakdown and didn't get back until half-past two or later. I went straight to bed but, of course I didn't know that my uncle wasn't home."

(BNC, 1987, WR)

s. I raised the window, laid hold of the poor bird, and launched it into the air, where it sailed off until out of my sight. 
(COCA, 1995, ACAD)

t. I did not see her again until during the afternoon lessons, when I noticed that she had been sent to stand alone in the middle of the schoolroom.

(BNC, 1990,WR)

u. I waited until before dinner to tell Charlie what Hutch had said.

(COCA, 1991, FIC)

$\mathrm{v}$. He is one of the oldest of the candidates, and, to that extent, it will postpone the real battle among the younger men until beyond the election.

(WB, 1990, SP)

The observations of the pattern [until + a preposition] in (20) reveal that the prepositions implying time such as date, age are mainly used in the pattern. Semantically, the meanings of until and the prepositions are put together into the pattern. However, semantically different prepositions from the prepositions implying time are used with until in $(20 \mathrm{j})(\mathrm{i} . \mathrm{e}$. with), $(20 \mathrm{q})(\mathrm{i} . \mathrm{e}$. from $),(20 \mathrm{~s})(\mathrm{i} . \mathrm{e}$. out of), and $(20 \mathrm{v})(\mathrm{i} . \mathrm{e}$. beyond). Also prepositions, which are used less than five times in corpora and not used to mean time such as inside, through, down, under, are used with until. Elements following the pattern [until + a preposition] show events, manners, and places like until with the help, until from the other table, until out of my sight, until beyond the election, until inside the rooms, until through the campus, until down the road, and until under thighs, which means that prepositions implying events, manners, and places are used with until. Consequently, it is made clear that until is used with prepositions implying either time on one hand or events, manners, and places on the other hand, but the former prepositions are mainly used with until.

\section{Implication of the Study}

Features of what kinds of prepositions co-occur with until discussed in the study help to systematically describe CPs including until in phraseological research. Inner features of how a word-combination undergoes the process to become a PU shown in the Section 4 based on Inoue $(2009,2016)$ are applicable to until before and until by and then might be useful to explain whether newly born word-combinations in present-day English are PUs.

\section{Concluding Remarks}

I have descriptively shown that until before and until by are newly observed PUs as well as CPs. The study has demonstrated the features of prepositions following until. Based on the research results of the study, I will show what prepositions are used together and will find out the rules to behave as CPs.

\section{Acknowledgment}

This research was made possible by the Grant-in-Aid for Young Scientists (B) (Grant number 17K13480). I would like to thank the Japan Society for the Promotion of Science.

\section{References}

Akimoto, M. (1999). Idiomatization and grammaticalization of complex prepositions. In S. J. Hwang \& A. R. Lommel (Eds.), The Twenty-second LACUS Forum (Vol. XXV, pp. 389-397).

Akimoto, M. (2002). Bunpouka to Idiom (Grammticalization and Idioms). Tokyo: Hitsujisyobo.

Akimoto, M. (2005). Fukugouzentishi nitsuite (About complex prepositions). Eigo Goho Bunpo Kenkyu (Research on English Grammar and Usage), 12, 5-18.

Ando, S. (2005). Gendai Eibunpou Kougi (Lectures on Modern English Grammar). Tokyo: Kaitakusha.

British National Corpus (BNC).

Corpus of Contemporary of American English (COCA).

Corpus of Historical American English (COHA).

Hoffman, S. (2001). In (hot) pursuit of data: Complex prepositions in late modern English. In P. Collins \& A, Smith (Eds.), New Frontiers of Corpus Research Amsterdam: Rodopi.

Hoffman, S. (2004). Are low-frequency complex prepositions grammaticalized?: On the limits of corpus data and the importance of intuition. In H. Lindquist \& C. Mair (Eds.), Corpus Approaches to Grammaticalization in English (pp. 171-200). Amsterdam: JohnBenjamins Publishing Company.

Hoffman, S. (2005). Grammaticalization and English Complex Prepositions: A Corpus-Based Study. London: 
Routledge.

Huddleston, R., \& Pullum, G. K. (2002). The Cambridge Grammar of the English Language. Cambridge: Cambridge University Press. https://doi.org/10.1017/9781316423530

Inoue, A. (2009). A problem of phonetic notation - stress patterns of set phrases including "day" in dictionaries. English Phonetics, 13, 125-134.

Inoue, A. (2011). A phraseological approach to finding the functions of newly observed compound prepositional phrases until to and up until to in contemporary English. Lexicography: Theoretical and Practical Perspective (pp. 160-169). ASIALEX (Asian Association for Lexicography)'11 Proceedings.

Inoue, A. (2013a). Newly observed phraseological units in present-day English: the example of be in and out. Lexicography and Dictionaries in the Information Age (Selected papers from the 8th ASIALEX International Conference), pp. 145-160.

Inoue, A. (2013b). Gendaieigo ni kansatsusareru shinkasuru teikeihyougen to sono jittai - yuugoukei in and of itself to haseikei in and of wo reitoshite (Evolutionary phraseological units in contemporary English -in and of itself as a merged form and in and of as a directive form). JASEC Bulletin, 22(1), 1-15.

Inoue, A. (2014). Actual behaviors of newly observed phraseological units comprising two prepositions. International Journal of English Linguistics, 4(4), 74-87. https://doi.org/10.5539/ijel.v4n4p74

Inoue, A. (2016). An eclectic phraseological research on the formation and degrammaticalization of phraseological units. International Journal of English Linguistics, 6(4), 1-11. https://doi.org/10.5539/ijel.v6n4p1

Ishibashim K. (Ed.). (1966). Eigo Gohou Daijiten (A Dictionary of Current English Usage • I). Tokyo: Taishyukansyoten.

Longman Dictionary of Contemporary English for Advanced Learners (6th ed.). (2014). London: Longman. $\left(L D C E^{6}\right)$

Macmillan English Dictionary for Advanced Learners (2nd ed.). (2007). Oxford: Macmillan Education. (MED $\left.{ }^{2}\right)$

Oxford Advanced Learner's Dictionary (9th ed.). (2015). Oxford: Oxford University Press. (OALD $\left.{ }^{9}\right)$

Oxford English Dictionary on Historical Principle 2nd edition on CD-ROM (Version 2.0). (2000). Oxford: Oxford University Press. $\left(O E D^{2}\right)$

Quirk, R., \& Mulholland, J. (1968). Complex prepositions and related sequences. In R. Quirk (Ed.), Essays on the English Language: Medieval and Modern (pp. 148-160). London: Longman.

Quirk, R., Greenbaum, S., Leech, G., \& Svartvik, J. (1985). A Comprehensive Grammar of the English Language. London: Longman.

Tottie, G., \& Hoffman, S. (2001). Based on: From dangling participle to complex prepositions. In K. Aijimer (Ed.), A Wealth of English (pp. 1-12). Gothenburg: Gothenburg University.

Vendler, X. (1967). Linguistics in Philosophy. U.S.: Cornell University Press.

WordBanksOnline (WB).

Yagi, K. (1999). Eigo no Bunpo to Goho - Imikara no Approach (A Semantic Descriptive Approach to Modern English). Tokyo: Kenksyusha Syuppan.

Yasui, M. (Ed.). (1996). Reikai Gendai Eibunpou Jiten (The Taishukan Explanatory Dictionary of Contemporary English Grammar). Tokyo: Taishyukansyoten.

\section{Notes}

Note 1. Quirk et al. (1985: 669) refer to a group preposition as a complex preposition and admit two-word sequences and three-word sequences. Also, Quirk et al. (1985: 671) explain a group preposition as follows (Please note that a complex preposition used in Quirk et al. (1985) is a group preposition: "In the strict definition, a complex preposition is a sequence that is indivisible both in terms of syntax and in terms of meaning,... Rather, there is a scale of 'cohesiveness' running from a sequence which behaves in every way like a simple preposition, to one which behaves in every way like a set of grammatically separate units...." Quirk et al. (1985: 671) shows the following nine criteria to judge whether a word-combination formed by [a preposition $1+\mathrm{a}$ noun $+\mathrm{a}$ preposition 2] is a group preposition. 
(1) a. Prep 2 can be varied: on the shelf at (but not: *in spite for)

b. The noun can be varied as between singular and plural: on the shelves by (the door) (but not: *in spites of)

c. The noun can be varied in respect of determiners: on a/ the shelf by; on shelves by (the door) (but not: * in a/the spite of)

d. Prep 1 can be varied: under the shelf by (the door) (but not: *for spite of)

e. Prep + complement can be replaced by a possessiveness pronoun: on the surface of the table $\sim$ on its surface (but in spite of the result $\sim$ * in its spite)

f. Prep $2+$ complement can be omitted: on the shelf (but not: *in spite)

g. Prep $2+$ complement can be replaced by a demonstrative: on that shelf (but not: *in that spite)

h. The noun can be placed by nouns of related meaning: on the ledge by (the door) (but not: *in malice of)

i. The noun can be freely modified by adjectives: on the low shelf by (the door) (but not: *in evident spite of)

Note 2. Word-formation rules are as follows: compounding, derivation, borrowing, conversion, acronym, backformation, shortening, blending, lexicalization of phrases, metaanalysis, and root creation.

Note 3. Accomplishment is the term used in Vendler (1967) to classify verbs into the following types: accomplishment, activity, achievement, and state.

\section{Copyrights}

Copyright for this article is retained by the author, with first publication rights granted to the journal.

This is an open-access article distributed under the terms and conditions of the Creative Commons Attribution license (http://creativecommons.org/licenses/by/4.0/). 